\title{
Migration from NetWISP to Nutritics - a quality control procedure
}

\author{
By S. Cassidy, B. Phillips, J. Caldeira Fernandes da Silva, A. Parle
}

safefood, 7 Eastgate Avenue, Little Island, Co. Cork, Republic of Ireland

\section{Introduction}

- safefood recipes online display FSA Front of Pack nutrition labelling ${ }^{(1)}$.

- $59 \%$ of consumers show interest in diet and health advice, $55 \%$ trust government websites $^{(2)}$.

- Recipes are a main driver to the safefood website, generating 1,000 2,000 views daily.

- safefood used NetWISP to analyse recipes. This platform is no longer supported. Migration to a new software was necessary. Nutritics was identified as most suitable.

\section{Aim}

To identify variability in nutrition information when using different software programs

\section{Methods}

- The migration process was undertaken in September 2017.

- As a quality control, 35 recipes were selected at random for re-analysis using NetWISP and Nutritics - 10 breakfast, 10 lunch, 10 dinner and 5 dessert.

- Differences in macronutrients and salt between software packages were identified for all recipes.

- Mean percentage variance across micro and macronutrients were calculated.

\section{Results}

All recipes displayed variance of greater than $20 \%$.

Saturated fat and salt showed the greatest mean differences of $76.3 \%$ and $71.9 \%$, respectively.

- $\quad$ Lower salt was observed in 32 recipes analysed on Nutritics.

- $\quad$ Values for saturated fat were higher in 21 recipes analysed on Nutritics.

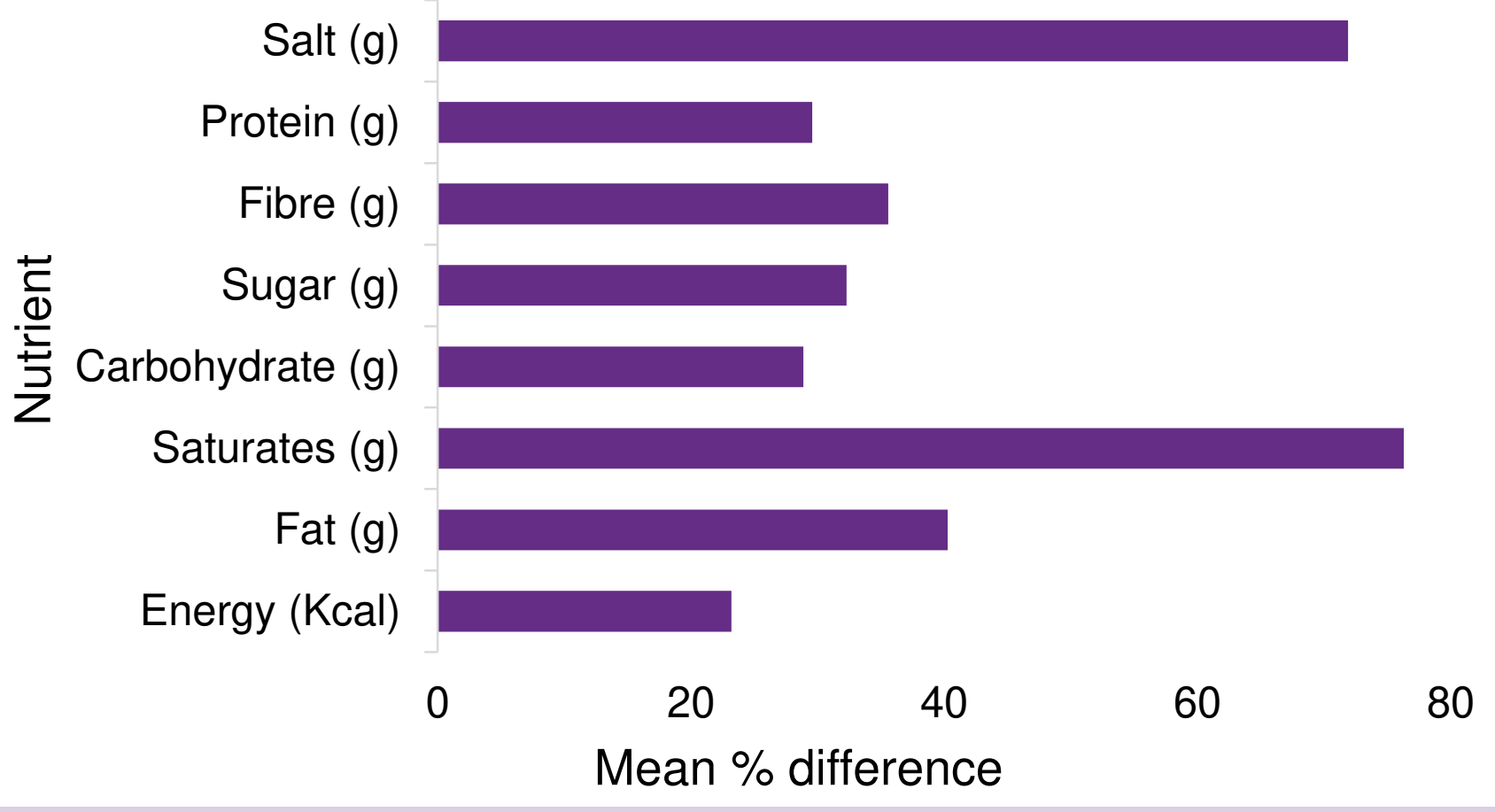

Figure 1 Mean difference in nutrients, expressed as a percentage, between software packages for all recipes

\begin{tabular}{|l|l|}
\hline Nutrient & $\begin{array}{l}\text { Range in macronutrients and salt } \\
\text { between software packages for all } \\
\text { recipes }\end{array}$ \\
\hline Energy (Kcal) & $1.0-160.0$ \\
\hline Fat (saturates) (g) & $0.0-10.1(0.0-2.9)$ \\
\hline Carbohydrate (sugars) (g) & $0.02-18.0(0.0-8.5)$ \\
\hline Fibre (g) & $0.0-3.2$ \\
\hline Protein (g) & $0.0-17.0$ \\
\hline Salt (g) & $0.0022-0.6$ \\
\hline
\end{tabular}

Table 1 Range for nutrients between software packages for all recipes

\section{Discussion \& Conclusions}

Considerable differences between software packages were identified. Major reasons include:

- Food composition and food label data differ. Nutritics presents food label data whilst NetWISP displayed food composition data.

- NetWISP used an older food composition database. This didn't reflect recent product reformulation.

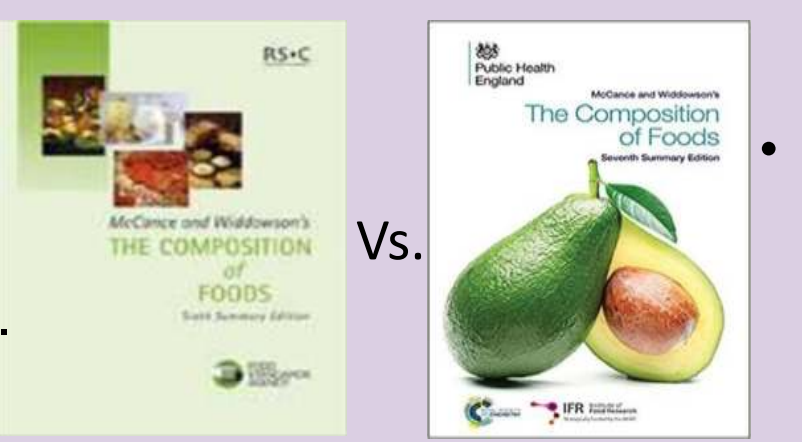

- A salt reduction programme was introduced in 2003, reducing the salt content of many processed meats, breads, breakfast cereals and spreadable fats ${ }^{(3)}$.

Introduction of new foods, farming and fortification practices and methods of preparation and cooking all cause alterations in food composition.

\section{Nons Food Safety}

Monitoring of Sodium and Potassium in Processed Foods Period:

September 2003 to March 2018

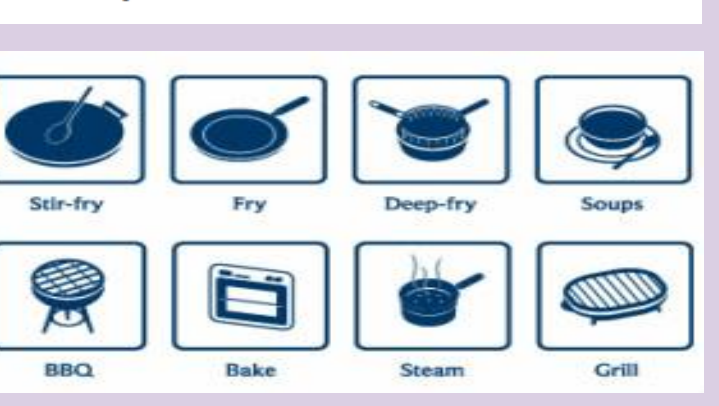

Conclusion: This quality control exercise highlights the importance of understanding differences between nutritional analysis programmes and using up-to-date software in an environment of product reformulation.

\section{References}

1. Department of Health, Food Standards Agency. Guide to creating a front of pack (FoP) nutrition label for pre-packed products sold through retail outlets. London; 2013.

2. Douglas N, Matthews M. B\&A Sign of the Times 2018. Dublin; 2018.

3. Food Safety Authority of Ireland. Monitoring of sodium and potassium in processed foods. Dublin: Food Safety Authority of Ireland,; 2003-2018. 